\title{
Danggui-Sayuk-Ga-Osuyu-Senggang-Tang ameliorates cold-induced vasoconstriction in vitro and in vivo
}

\author{
KANGWOOK LEE ${ }^{1}$, SUNG-GOOK CHO ${ }^{2}$, SANG-MI WOO ${ }^{3}$, AH JEONG KIM ${ }^{1}$, KANG MIN LEE ${ }^{1}$, \\ HO YEON GO ${ }^{4}$, SEUNG-HO SUN ${ }^{5}$, TAE-HUN KIM ${ }^{6}$, KI-YONG JUNG ${ }^{7}$, YOU-KYUNG CHOI ${ }^{7}$, EUN MEE LIM ${ }^{8}$, \\ YUN-KYUNG SONG ${ }^{9}$, JONG-HYEONG PARK ${ }^{7}$, CHAN-YONG JUN ${ }^{7}$ and SEONG-GYU KO ${ }^{10}$ \\ ${ }^{1}$ Department of Science in Korean Medicine, Graduate School, Kyung Hee University, Seoul 130-701; \\ ${ }^{2}$ Department of Biotechnology, Korea National University of Transportation, Chungbuk 368-701; \\ ${ }^{3}$ Department of Cancer Preventive Material Development, Graduate School, Kyung Hee University, Seoul 130-701 \\ ${ }^{4}$ Department of Korean Internal Medicine, College of Korean Medicine, Semyung University, Chungju 380-960; \\ ${ }^{5}$ Department of Oriental Internal Medicine, College of Korean Medicine, Sangji University, Wonju 220-702; \\ ${ }^{6}$ Korean Medicine Clinical Trial Center, Korean Medicine Hospital, Kyung Hee University, Seoul 130-701; \\ Departments of ${ }^{7}$ Korean Internal Medicine, ${ }^{8}$ Obsterics and Gynecology and ${ }^{9}$ Korean Rehabilitation Medicine, \\ College of Korean Medicine, Gachon University, Seongnam 461-701; ${ }^{10}$ Department of Preventive Medicine, \\ College of Korean Medicine, Kyung Hee University, Seoul 130-701, Republic of Korea
}

Received May 26, 2015; Accepted August 5, 2016

DOI: $10.3892 / \mathrm{mmr} .2016 .5805$

\begin{abstract}
Danggui-Sayuk-Ga-Osuyu-Senggang-Tang (DSGOST), one of the traditional Chinese medicines, has long been prescribed for patients suffering from Raynaud phenomenon (RP) in Northeast Asian countries, including China, Japan and Korea. Although a previous in vitro study from our laboratory revealed that DSGOST prevents cold $\left(25^{\circ} \mathrm{C}\right)$-induced RhoA activation and endothelin-1 (ET-1) production in endothelial cells (ECs), the mechanisms by which DSGOST is able to alleviate the symptoms of RP have yet to be fully elucidated. The present study aimed to demonstrate that DSGOST regulates RhoA-mediated pathways in cold-exposed pericytes. In pericytes, DSGOST amplified cold-induced RhoA activation, while markedly reducing ET-1-induced RhoA activation. Additionally, DSGOST-mediated regulation of RhoA was closely associated with Rho-associated, coiled-coil-containing protein
\end{abstract}

Correspondence to: Professor Chan-Yong Jun, Department of Korean Internal Medicine, College of Korean Medicine, Gachon University, Bokjeong-dong, Sujeong-gu, Seongnam 461-701, Republic of Korea

E-mail: joncy@gachon.ac.kr

Professor Seong-Gyu Ko, Department of Preventive Medicine, College of Korean Medicine, Kyung Hee University, Hoegi-dong, Dongdaemun-gu, Seoul 130-701, Republic of Korea

E-mail: epiko@khu.ac.kr

Key words: Danggui-Sayuk-Ga-Osuyu-Senggang-Tang, Raynaud's phenomenon, cold-induced vasospasm, actin reorganization, pericytes, $\alpha 2 \mathrm{c}$ adrenergic receptor kinase 1 (ROCK1)/testis-specific kinase 1 (TESK1)/PDXP, but not with LIM domain kinase 1/2 (LIMK1/2), cofilin and myosin light chain (MLC). Thus, DSGOST activation of RhoA/ROCK1/TESK1/PDXP in cold-exposed pericytes appeared to be crucial for treating vessel contraction. In addition, the DSGOST effect on the RhoA-mediated pathway in cold-induced human umbilical vein endothelial cells or human dermal microvascular endothelial cells was similar to that in ET-1-treated pericytes, but not in cold-induced pericytes. The results of the present study further confirmed that DSGOST inhibits cold-induced contraction of the mouse tail vein in vivo. Furthermore, DSGOST treatment reduced cold-induced expression of the $\alpha 2 \mathrm{c}$-adrenergic receptor in mouse tail vessels. Therefore, the data in the present study suggest that DSGOST may be useful for the treatment of RP-like disease.

\section{Introduction}

Raynaud's phenomenon (RP) is characterized by prolonged vasoconstriction and reduced blood flow in cutaneous capillaries and arterioles upon cold stress $(1,2)$. This intensified contraction leads to a chilly sensation at the extremities of the hands or feet, although contributing to minimize heat loss from the body $(3,4)$, suggesting that the development of drugs for relieving an abnormal vasospasm would be useful for RP treatment. This vessel contraction is regulated by RhoA-mediated signaling pathways in vascular cells, including endothelial cells (ECs), vascular smooth muscle cells (VSMCs) and pericytes (5-7). In RP, cold-induced RhoA activation in ECs regulates the production of endothelin-1 (ET-1), which is considered to be a key vasoconstrictor in RP-like disease (8-10). In capillary vessels, ET-1 released from ECs promotes actin reorganization in pericytes that are 
undergoing constriction (11). EC-derived ET-1 also activates the RhoA pathway in VSMCs within arterioles, and this activation is responsible for translocation of the $\alpha 2 \mathrm{c}$ adrenergic receptor $(\alpha 2 \mathrm{c}-\mathrm{AR})$ from the Golgi apparatus to the plasma membrane (12-14). $\alpha 2 c-A R$ is predominantly involved in cold-induced vasoconstriction in RP (14-18). Therefore, inhibiting the cold-induced RhoA pathway may be a useful strategy for RP treatment.

Traditional Chinese medicine (TCM) theory-based formulas have been used for RP patient therapy, and one of the TCM-based herbal medicines, Danggui-Sayuk-Ga-Osuyu-Senggang-Tang (DSGOST), has been clinically applied to patients in order to relieve coldness and other RP-like symptoms (19-22). DSGOST led to an improvement in the peripheral circulation with an elevated temperature in the rat (23). Furthermore, a previous in vitro study performed in our laboratory revealed that DSGOST inhibits cold-derived contraction of ECs and VSMCs through the inhibition of both RhoA activation and production of ET-1 and translocation of $\alpha 2 \mathrm{c}-\mathrm{AR}$ (24). Therefore, DSGOST may be an effective agent for RP treatment. However, the effects of DSGOST on RP treatment have yet to be fully elucidated via either in vitro or in vivo studies.

Based on the results of our previous in vitro study (24), the present study aimed to further evaluate the mitigative effects of DSGOST on cold-induced vasoconstriction. DSGOST inhibited cold- and ET-1-provoked contraction of both pericytes and ECs, with decreased activity of the RhoA-associated contractile pathway. In addition, orally administered DSGOST prevented the reduction in the vessel area of the mouse tail from occurring. Furthermore, DSGOST mitigated cold-induced vasoconstriction with a reduced staining intensity for CD31 and $\alpha 2 c-A R$ in mice. Therefore, our present data suggest that DSGOST exerts beneficial effects in terms of relieving the cold response in microvessels in RP-like disease.

\section{Materials and methods}

Preparation of DSGOST. DSGOST powder was prepared as previously described (24). In brief, herbal components of DSGOST were mixed and subsequently extracted by hot water (10-fold volume), comprising $1 \mathrm{~g}$ Angelica radix, $1 \mathrm{~g}$ Cinnamomi cortex, $1 \mathrm{~g}$ Paeoniae root, $1 \mathrm{~g}$ Akebia root, $0.67 \mathrm{~g}$ Asarum, $0.67 \mathrm{~g}$ Glycyrrhiza, $1.67 \mathrm{~g}$ Zizyphus jujuba, $0.67 \mathrm{~g}$ Evodia fruit and $1.33 \mathrm{~g}$ Ginger root. The dried mixture was stored at $-80^{\circ} \mathrm{C}$ until use. The composition of the DSGOST herbal prescription is shown in Table I.

Cell culture. Human umbilical vein endothelial cells (HUVECs), human dermal microvascular endothelial cells (HDMECs) and pericytes were purchased from ScienCell Research Laboratories, Inc. (Carlsbad, CA, USA). HUVECs and HDMECs were cultured in endothelial medium supplemented with $5 \%$ fetal bovine serum and $1 \%$ endothelial cell growth supplement (ScienCell Research Laboratories, Inc.). Pericytes from human brain microvessels were cultured in pericyte medium (ScienCell Research Laboratories, Inc.) supplemented with 5\% fetal bovine serum (ScienCell Research Laboratories, Inc.), $1 \%$ pericyte growth supplement and $1 \%$ penicillin/streptomycin solution.
Table I. Composition of the Danggui-Sayuk-Ga-OsuyuSenggang-Tang herbal prescription (total, $9.01 \mathrm{~g}$ ).

\begin{tabular}{|c|c|c|c|}
\hline $\begin{array}{l}\text { Korean } \\
\text { name }\end{array}$ & $\begin{array}{c}\text { Chinese } \\
\text { name }\end{array}$ & $\begin{array}{c}\text { Scientific/ } \\
\text { common name }\end{array}$ & Amount (g) \\
\hline Danggui & Danggui & Angelica radix & 1 \\
\hline Geji & Guizhi & Cinnamomi cortex & 1 \\
\hline Jakyak & Bai shao & Paeoniae root & 1 \\
\hline Moktong & Mutong & Akebia root & 1 \\
\hline Sesin & Xixin & Asarum & 0.67 \\
\hline Gamcho & Gancao & Glycyrrhiza & 0.67 \\
\hline Daechu & Dazao & Zizyphus jujuba & 1.67 \\
\hline Osuyu & Wuzhuyu & Evodia fruit & 0.67 \\
\hline Saenggang & Shengjian & Ginger root & 1.33 \\
\hline
\end{tabular}

In vitro studies. For cold-mediated contraction, endothelial cells and pericytes were pretreated with DSGOST $(100 \mu \mathrm{g} / \mathrm{ml})$ for $30 \mathrm{~min}$, and subsequently cultured at physiological temperature $\left(37^{\circ} \mathrm{C}\right)$ or a cooler temperature $\left(25^{\circ} \mathrm{C}\right)$ for $30 \mathrm{~min}$. In case of ET-1-mediated pericyte contraction, instead of the cooler condition (i.e. at $25^{\circ} \mathrm{C}$ ), pericytes were incubated with ET-1 (Sigma-Aldrich; Merck Millipore, Darmstadt, Germany). Following the incubation at the cooler temperature with ET-1, cells were harvested for protein extraction using iced radioimmunoprecipitation assay (RIPA) buffer. The extracted proteins were mixed with sample buffer and boiled at $100^{\circ} \mathrm{C}$ for $10 \mathrm{~min}$. The boiled samples were separated using 8-12\% SDS-PAGE according to their molecular weights, and then transferred to a nitrocellulose membrane for western blotting. The proteins were blotted using the following antibodies: Rabbit anti-phospho-cofilin (Ser3) monoclonal (cat. no. 3313; 1:1,000), rabbit anti-phospho-LIM domain kinase (LIMK)1 (Thr508)/LIMK2 (Thr505) polyclonal (cat. no. 3841; 1:1,000), rabbit anti-testis-specific kinase 1 (TESK1) monoclonal (cat. no. 4655; 1:1,000), rabbit anti-PDXP monoclonal (cat. no. 4686; 1:1,000) and rabbit anti-phospho-myosin light chain 2 (Ser19; cat. no. 3671; 1:1,000) antibodies (Cell Signaling Technology, Inc., Danvers, MA, USA) and mouse-anti-RhoA-GTP monoclonal antibody (cat. no. 26904; 1:500; NewEast Biosciences, Malvern, PA, USA).

In vivo studies. Six-week-old BALB/c mice were purchased from Jungang Lab Animal, Inc. (Seoul, Korea). Mice were housed under conditions of a constant temperature $\left(24 \pm 2^{\circ} \mathrm{C}\right)$ with $12 \mathrm{~h}$-light/ $12 \mathrm{~h}$-dark cycle. All experimental procedures were approved by the Kyung Hee University Institutional Animal Care and Use Committee (KHU-IACUC). Mice were randomly grouped and administered orally with drinking water or DSGOST $(10 \mathrm{mg} / \mathrm{kg})$. After $30 \mathrm{~min}$, mice were anesthetized using Avertin solution which was prepared by mixing 2,2,2-tribromoethanol (Sigma-Aldrich; Merck Millipore) and 2-methyl-2-butanol, tertiary amyl alcohol 99\% (Sigma-Aldrich; Merck Millipore), according to the manufacturer's protocol. Subsequently, their tails were soaked under cool $\left(25 \pm 2^{\circ} \mathrm{C}\right)$ or warm $\left(37 \pm 2^{\circ} \mathrm{C}\right)$ water for $30 \mathrm{~min}$, using a heat block to maintain constant temperature. The $10 \mathrm{~mm}$ length of the segment from 
A

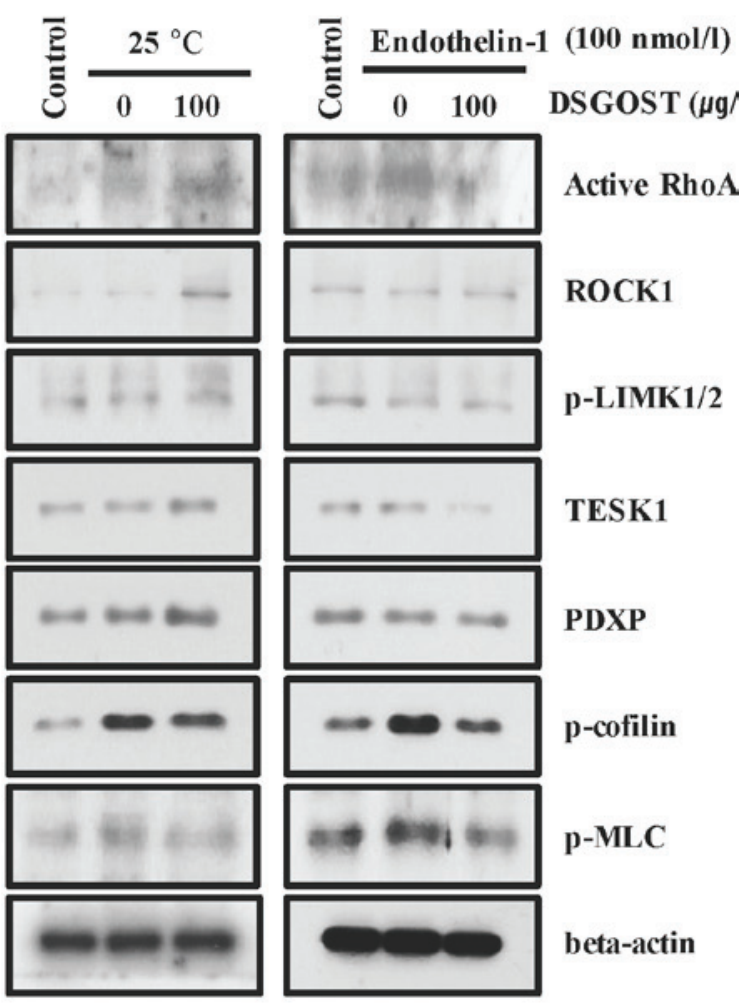

B
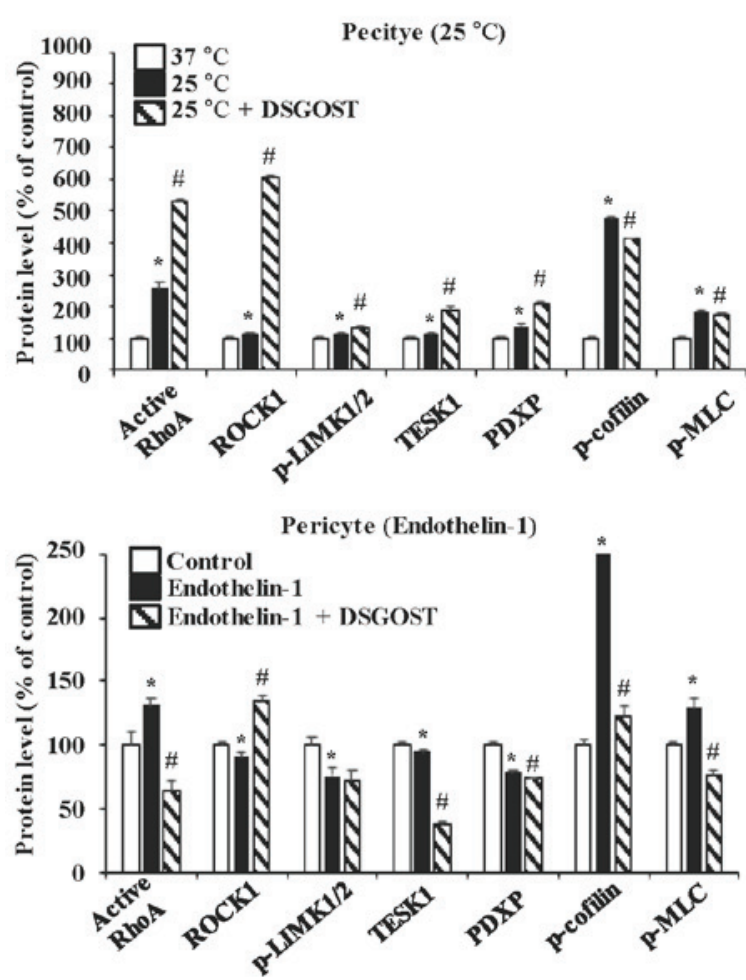

Figure 1. Inhibitory effects of DSGOST on cold- and ET-1-induced contraction-associated signaling molecules in pericytes. (A) Effects of DSGOST on protein expression in cold (left panels)- orET-1 (right panels)-exposed pericytes was determined using western blotting. $\beta$-actin was used as a loading control Three independent experiments were performed. (B) The protein expression shown in (A) was quantified by densitometric analysis of the western blots. Values are expressed as the mean \pm standard deviation. ${ }^{*} \mathrm{P}<0.05$ vs. $37^{\circ} \mathrm{C}$; ${ }^{\prime \prime} \mathrm{P}<0.05$ vs. $25^{\circ} \mathrm{C}$. DSGOST, Danggui-Sayuk-Ga-Osuyu-Senggang-Tang; ET-1, endothelin-1; GTP, guanosine triphosphate; ROCK1, Rho-associated, coiled-coil-containing protein kinase 1 ; p-LIMK1/2, phosphorylated LIM domain kinase 1/2; TESK1, testis-specific kinase 1; PDXP, pyridoxal phosphatase; p-MLC, phosphorylated myosin light-chain kinase.
A

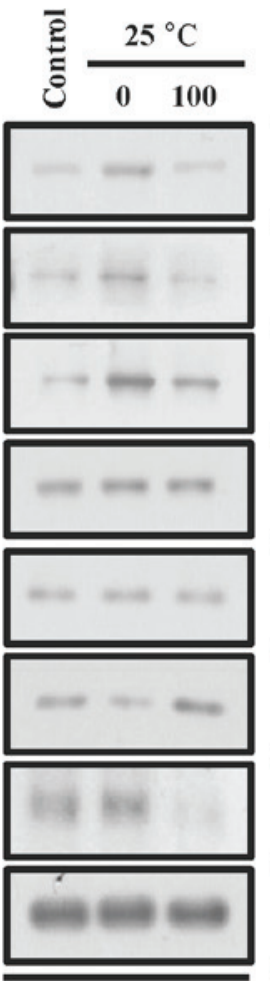

HUVEC

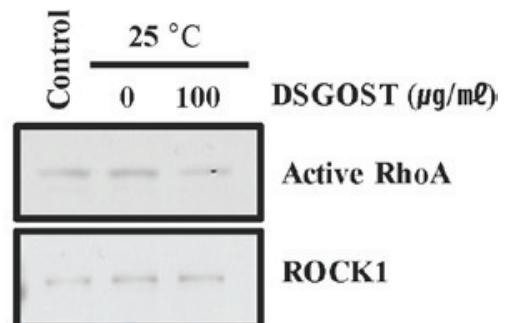

p-LIMK1/2

TESK1

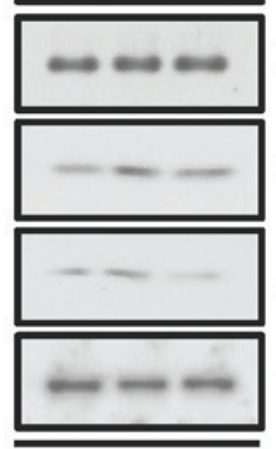

PDXP

p-cofilin

p-MLC

beta-actin

HDMEC

HUVEC

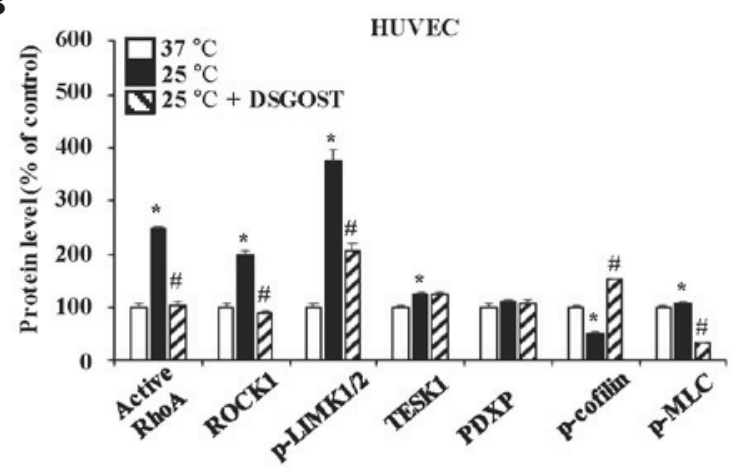

HDMEC

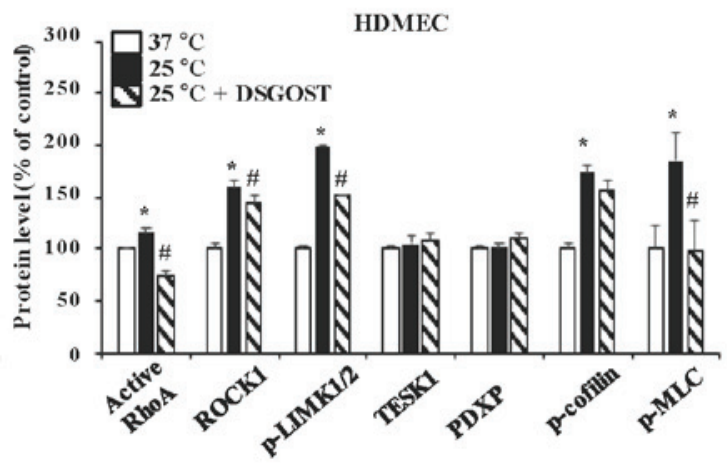

Figure 2. Inhibitory effects of DSGOST on cold-induced contraction-associated signaling molecules in vascular endothelial cells. (A) Protein expression in cold-exposed HUVECs (left panels) and HDMECs (right panels) were determined by western blot analysis. Three independent experiments were performed. $\beta$-actin was used as a loading control. (B) The protein expression in (A) was quantified by densitometric analysis of western blots. Values are expressed as the mean \pm standard deviation. ${ }^{*} \mathrm{P}<0.05$ vs. $37^{\circ} \mathrm{C}$; ${ }^{*} \mathrm{P}<0.05$ vs. $25^{\circ} \mathrm{C}$. DSGOST, Danggui-Sayuk-Ga-Osuyu-Senggang-Tang; ET-1, endothelin-1; GTP, guanosine triphosphate; ROCK1, Rho-associated, coiled-coil-containing protein kinase 1; p-LIMK1/2, phosphorylated LIM domain kinase 1/2; TESK1, testis-specific kinase 1; PDXP, pyridoxal phosphatase; MLC, myosin light-chain kinase; HDMEC, human dermal microvascular cell; HUVEC, human umbilical vein endothelial cell. 
A

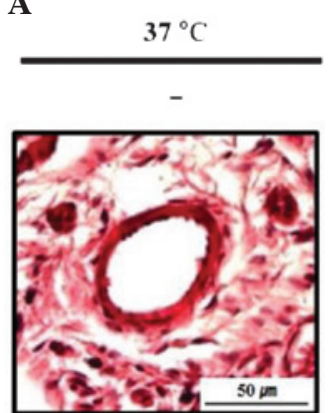

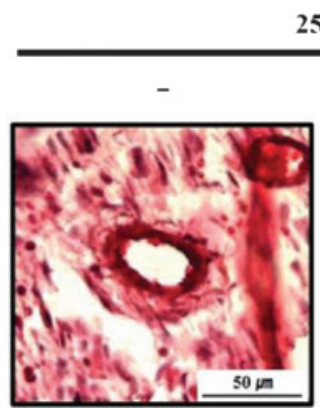

$25^{\circ} \mathrm{C}$

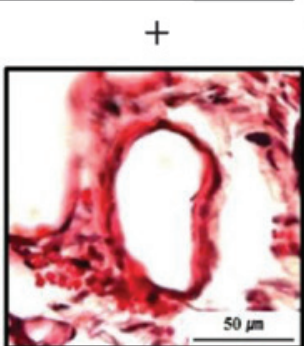
DSGOST

B

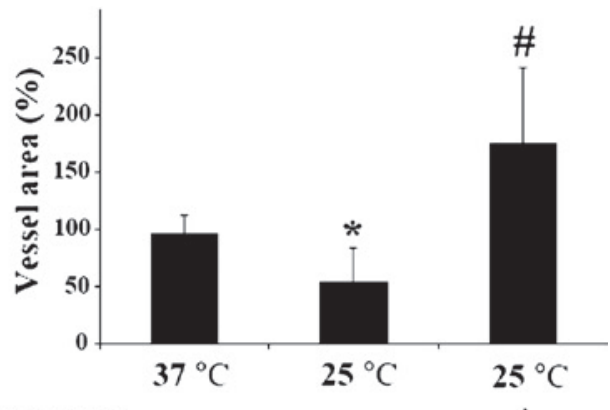

Figure 3. Mitigative effects of DSGOST on vasoconstriction at the mouse tails. Mice were treated with vehicle or DSGOST extract (10 mg/kg) and exposed ( $n=5 /$ group). The extremities of their tails were prepared for H\&E staining. The bar indicates $50 \mu \mathrm{m}$. (A) Representative images of H\&E-stained tail sections from each group (magnification, 40x): $37^{\circ} \mathrm{C}$ group (top left); $25^{\circ} \mathrm{C}$ group (top middle); and DSGOST group (top right). (B) The vessel area was measured using ImageJ software. Data are shown as the mean \pm standard deviation $\left(" \mathrm{P}<0.05,37^{\circ} \mathrm{C}\right.$ group vs. $25^{\circ} \mathrm{C}$ group; ${ }^{*} \mathrm{P}<0.05,25^{\circ} \mathrm{C}$ group vs. DSGOST group). DSGOST, Danggui-Sayuk-Ga-Osuyu-Senggang-Tang; H\&E, hematoxylin and eosin.

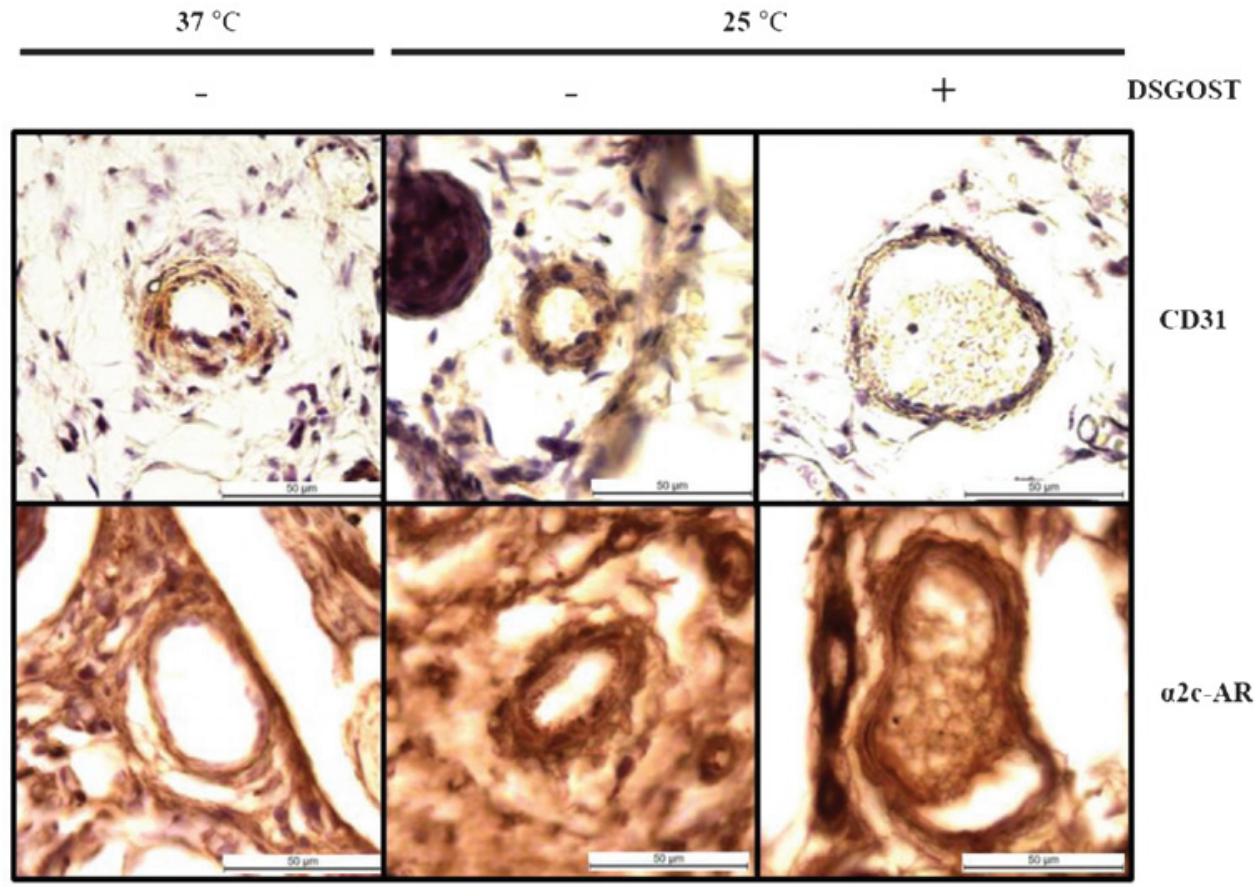

Figure 4. Effect of DSGOST on the protein expression of CD31 and $\alpha 2 \mathrm{C}$-aAR in tail vessels. Mice were administered drinking water or DSGOST (10 mg $/ \mathrm{kg}$ ) and exposed to each of the designated temperatures ( $n=5 /$ group). The tail tissues were stained with anti-CD31 and $\alpha 2 \mathrm{c}-\mathrm{AR}$ antibodies, and images were captured of the stained sections at a magnification of 40x. The bar indicates $50 \mu \mathrm{m} . \alpha 2 \mathrm{C}$-aAR, $\alpha 2 \mathrm{C}$-adrenoceptor; DSGOST, Danggui-Sayuk-Ga-Osuyu-Senggang-Tang.

extremities of the tail were fixed in formaldehyde and embedded in paraffin. The paraffin blocks were sectioned at $15 \mu \mathrm{m}$ and mounted on slide glasses. For hematoxylin and eosin (H\&E) staining, the prepared slides were immersed in H\&E solution for staining the nuclei and the cytoplasm. The stained sections were photographed at a magnification of $40 x$, and subsequently the area of the vessels from each group was measured using ImageJ software (National Institutes of Health, Bethesda, MD, USA). Immunohistochemistry was performed using a Vextastain ${ }^{\circledR}$ ABC-AP kit, according to the manufacturer's protocol (Vector Laboratories, Burlingame, CA, USA). Rabbit anti- $\alpha 2$ c-AR polyclonal antibody (1:100) and rabbit anti-CD31 polyclonal antibody (1:100; Abcam, Cambridge, UK) were used, and the histological expression patterns of $\alpha 2 \mathrm{c}-\mathrm{AR}$ and CD31 were analyzed. Following staining with each of the antibodies, the sections were photographed at a magnification of $40 \mathrm{x}$.
Statistical analysis. Statistical analysis was performed using SPSS V22.0 (IBM SPSS, Armonk, NY, USA). The differences of the means between the groups were analyzed using one-way analysis of variance and a Student's t-test. $\mathrm{P}<0.05$ was used to indicate a statistically significant difference.

\section{Results}

Inhibitory effect of DSGOST on the cold- and ET-1-induced contractile pathway in pericytes. Since pericytes cause vessel contraction that is important for the processes of RP $(1,25)$, whether treatment with DSGOST inhibited contraction of either cold $\left(25^{\circ} \mathrm{C}\right)$ - or ET-1-exposed pericytes was first examined. DSGOST enhanced RhoA activation and increased the levels of ROCK1, TESK1 and PDXP in pericytes exposed to the cold, but not to ET-1, while slightly reducing the 
levels of LIMK1/2, cofilin and MLC for the two different conditions (Fig. 1). Therefore, DSGOST activation of the RhoA/ROCK/TESK1/PDXP pathway appeared to be unique to the cold-exposed pericytes.

Inhibitory effect of DSGOST on the cold-induced contractile pathway in vascular endothelial cells. Based on our previous work on the mitigative effects of DSGOST on the cold response in ECs (24), whether DSGOST affects the cold-induced RhoA pathway in ECs was subsequently investigated. DSGOST inhibited RhoA activation, the phosphorylation of LIMK1/2 and MLC, and reduced the level of ROCK1, with no effect on TESK1 and PDXP in cold-exposed ECs (Fig. 2).

Mitigative effects of DSGOST on cold-induced vasoconstriction. To investigate DSGOST efficacy on cold-mediated vessel contraction, the vessel area was measured following incubation under each condition. DSGOST treatment rescued cold-induced vessel contraction and appeared to markedly promote vasodilation (Fig. 3). Thus, our data suggested that DSGOST may be useful for relieving cold-induced vessel contraction.

Effect of DSGOST on $\alpha 2 c-A R$ in the tail vein. As increases in $\alpha 2 \mathrm{c}$-AR protein expression and the anterograde translocation of this protein to the plasma membrane occurs when cells are exposed to cooler temperatures (12-14), this protein was selected for the current investigation. In the immunohistochemical analysis, although $\alpha 2 \mathrm{c}-\mathrm{AR}$ was evidently detected in mouse tail vessels at $25^{\circ} \mathrm{C}$, DSGOST treatment reduced its induction in the vessel (Fig. 4). Therefore, the oral administration of DSGOST was demonstrated to be effective at reducing cold-induced vessel contraction.

\section{Discussion}

DSGOST has long been used to treat cold syndrome, including RP (19-23). Nevertheless, the molecular mechanisms underpinning its effects in RP have yet to be fully elucidated. In the present study, it has been revealed that DSGOST activates the RhoA/ROCK/TESK1/PDXP pathway in cold-exposed pericytes.

The findings in the present study are slightly different from those obtained previously by our group with respect to RhoA-mediated intracellular signaling (24). Although a role for pericytes in the regulation of EC function and blood flow is in common with a role of VSMCs, certain phenotypic differences between pericytes and VSMCs may afford a possible reason to account for the contrasting results of DSGOST in pericytes and VSMCs (5-7). For example, pericytes do not possess the calcium-binding protein, calponin, which is an important regulator of VSMC contraction (26). In addition, capillaries and arterioles derived from endothelial cells are covered and regulated by pericytes and VSMCs, respectively $(5,27)$. Furthermore, the source of VSMCs used in our previous study was human umbilical veins (24), whereas pericytes in the present study were derived from human brain microvessels. Understanding those above-mentioned differences may make it possible to explain the DSGOST effect on the RhoA-mediated pathway in cold-exposed pericytes. Furthermore, the results in the present study concerning DSGOST inhibition of the cold response in ECs are consistent with our previous findings that DSGOST suppresses cold-induced RhoA activation in ECs. From the in vivo experiments, DSGOST effectively inhibited cold-induced constriction of mouse tail vessels with decreased expression of $\alpha 2 \mathrm{c}-\mathrm{AR}$, which was used to evaluate coldness in RP (12-14,28,29). Taken together, the in vitro and in vivo data in the present study suggested that DSGOST may mitigate cold-stimulated vasoconstriction via inhibition of the RhoA-mediated contractile pathway in both pericytes and ECs for RP treatment, whereas it is has yet to be fully determined which active compounds of DSGOST have an inhibitory effect on pathological vasospasms in RP.

It was also revealed that DSGOST inhibits RhoA-mediated pathways for the phosphorylation of cofilin and MLC in coldand ET-1-exposed vascular cells, indicating that DSGOST may suppress contraction of vascular cells via regulation of actin reorganization (30-33). Based on DSGOST inhibition of either RhoA activation or cytoskeletal reorganization, it is hypothesized that DSGOST may be useful in the management of other diseases with dysregulation of actin cytoskeleton in vascular cells. For example, dysregulation of actin dynamics in vascular cells is likely to be important for tumor migration, invasion, angiogenesis and metastasis (34-36). Additionally, endothelial dysfunction with cytoskeletal dynamics is closely associated with vascular failure (37). Therefore, DSGOST is possibly useful for the treatment of diseases that are associated with dysregulation of actin reorganization.

In conclusion, it has been shown, to the best of our knowledge for the first time, that DSGOST inhibits the RhoA-mediated contractile pathway in cold- or ET-1-exposed vascular cells, and mitigates cold-induced vasoconstriction in mouse tail vein. Although the precise biological mechanism of DSGOST on RP treatment has yet to be fully elucidated, and there remains a requirement to know which metabolites of DSGOST effectively relieve cold-induced vasoconstriction, based on our findings it is hypothesized that DSGOST is beneficial for the treatment of RP-like disease.

\section{Acknowledgements}

This study was supported by the Korean Medicine R\&D Project of the Ministry of Health and Welfare (no. HI13C0530).

\section{References}

1. Cooke JP and Marshall JM: Mechanisms of Raynaud's disease. Vasc Med 10: 293-307, 2005.

2. LeRoy EC and Medsger TA Jr: Raynaud's phenomenon: A proposal for classification. Clin Exp Rheumatol 10: 485-488, 1992.

3. Kellogg DL Jr: In vivo mechanisms of cutaneous vasodilation and vasoconstriction in humans during thermoregulatory challenges. J Appl Physiol (1985) 100: 1709-1718, 2006.

4. van Marken Lichtenbelt WD and Schrauwen P: Implications of nonshivering thermogenesis for energy balance regulation in humans. Am J Physiol Regul Integr Comp Physiol 301: R285-R296, 2011.

5. Hamilton NB, Attwell D and Hall CN: Pericyte-mediated regulation of capillary diameter: A component of neurovascular coupling in health and disease. Front Neuroenergetics 2: 5, 2010.

6. Rajendran P, Rengarajan T, Thangavel J, Nishigaki Y, Sakthisekaran D, Sethi G and Nishigaki I: The vascular endothelium and human diseases. Int J Biol Sci 9: 1057-1069, 2013.

7. Webb RC: Smooth muscle contraction and relaxation. Adv Physiol Educ 27: 201-206, 2003. 
8. Zamora MR, O'Brien RF, Rutherford RB and Weil JV: Serum endothelin-1 concentrations and cold provocation in primary Raynaud's phenomenon. Lancet 336: 1144-1147, 1990.

9. Barman SA: Vasoconstrictor effect of endothelin-1 on hypertensive pulmonary arterial smooth muscle involves Rho-kinase and protein kinase C. Am J Physiol Lung Cell Mol Physiol 293: L472-L479, 2007.

10. Sakurada S, Okamoto H, Takuwa N, Sugimoto N and Takuwa Y: Rho activation in excitatory agonist-stimulated vascular smooth muscle. Am J Physiol Cell Physiol 281: C571-C578, 2001.

11. Dehouck MP, Vigne P, Torpier G, Breittmayer JP, Cecchelli R and Frelin C: Endothelin-1 as a mediator of endothelial cell-pericyte interactions in bovine brain capillaries. J Cereb Blood Flow Metab 17: 464-469, 1997.

12. Chotani MA, Flavahan S, Mitra S, Daunt D and Flavahan NA Silent alpha(2C)-adrenergic receptors enable cold-induced vasoconstriction in cutaneous arteries. Am J Physiol Heart Circ Physiol 278: H1075-1083, 2000.

13. Jeyaraj SC, Chotani MA, Mitra S, Gregg HE, Flavahan NA and Morrison KJ: Cooling evokes redistribution of alpha2C-adrenoceptors from golgi to plasma membrane in transfected human embryonic kidney 293 cells. Mol Pharmacol 60: 1195-1200, 2001.

14. Bailey SR, Eid AH, Mitra S, Flavahan S and Flavahan NA: Rho kinase mediates cold-induced constriction of cutaneous arteries: Role of alpha2C-adrenoceptor translocation. Circ Res 94: $1367-1374,2004$

15. Aburto TK, Lajoie C and Morgan KG: Mechanisms of signal transduction during alpha-2-adrenergic receptor-mediated contraction of vascular smooth-muscle. Circ Res 72: 778-785, 1993.

16. Aubdool AA, Graepel R, Kodji X, Alawi KM, Bodkin JV, Srivastava S, Gentry C, Heads R, Grant AD, Fernandes ES, et al: TRPA1 is essential for the vascular response to environmental cold exposure. Nat Commun 5: 5732, 2014.

17. Ekenvall L, Lindblad LE, Norbeck O and Etzell BM: Alpha-adrenoceptors and cold-induced vasoconstriction in human finger skin. Am J Physiol 255: H1000-H1003, 1988.

18. Faber JE: Effect of local tissue cooling on microvascular smooth muscle and postjunctional alpha 2-adrenoceptors. Am J Physiol 255: H121-H130, 1988.

19. Ninomiya F: Clinical evaluation of perspiration reducing effects of a kampo formula, shigyaku-san, on palmoplantar hidrosis. Evid Based Complement Alternat Med 5: 199-203, 2008

20. Kumura Y, Tanaka A and Sato H: Efficacy of kampo formula tokishigyakukagoshuyushokyoto for cold syndrome evaluated with a novel clinical method using a patient-based questionnaire database. Kampo Med 63: 299-304, 2012

21. Tsukada R, Yamaguchi T, Hang L, Iseki M, Kobayashi H and Inada E: Effect of a traditional Japanese medicine goshajinkigan, tokishigyakukagoshuyushokyoto on the warm and cold sense threshold and peripheral blood flow. Health (NY) 6: 757-763, 2014.
22. Hayashi A: A case of atypical facial pain treated with toki-sh igyaku-ka-goshuyu-shokyo-to. Kampo Medicine 50: 257-260, 1999.

23. Kanai S, Okano H and Abe H: Efficacy of toki-shigyakuka-go syuyu-syokyo-to (danggui-sini-jia-wuzhuyu-shengjiang-tang) on peripheral circulation in autonomic disorders. Am J Chin Med 25: 69-78, 1997

24. Cho SG, Go HY, Park JS, Jung KY, Sun SH, Choi YK, Song YK, Park JH, Jun CY and Ko SG: Herbal Prescription, DSGOST, prevents cold-induced RhoA activation and endothelin-1 production in endothelial cells. Evid Based Complement Alternat Med 2014: 549307, 2014.

25. Toi M, Takayanagi T, Souma R and Tominaga T: Inhibition of vascular endothelial growth-factor induced cell-growth by an angiogenesis inhibitor agm-1470 in capillary endothelial-cells. Oncol Rep 1: 423-426, 1994.

26. Bandopadhyay R, Orte C, Lawrenson JG, Reid AR, Silva S and Allt G: Contractile proteins in pericytes at the blood-brain and blood-retinal barriers. J Neurocytol 30: 35-44, 2001.

27. Cleaver O and Melton DA: Endothelial signaling during development. Nat Med 9: 661-668, 2003.

28. Chotani MA, Mitra S, Su BY, Flavahan S, Eid AH, Clark KR, Montague CR, Paris H, Handy DE and Flavahan NA: Regulation of alpha (2)-adrenoceptors in human vascular smooth muscle cells. Am J Physiol Heart Circ Physiol 287: H59-H67, 2004.

29. Thompson-Torgerson CS, Holowatz LA, Flavahan NA and Kenney WL: Cold-induced cutaneous vasoconstriction is mediated by Rho kinase in vivo in human skin. Am J Physiol Heart Circ Physiol 292: H1700-H1705, 2007.

30. Tsai CH and Lee YJ: Focus on ADF/Cofilin: Beyond actin cytoskeletal regulation. ISRN Cell Biol 2012: 1-7, 2012.

31. Wysolmerski RB and Lagunoff D: Involvement of myosin light-chain kinase in endothelial-cell retraction. Proc Natl Acad Sci USA 87: 16-20, 1990.

32. Chen XS, Pavlish K and Benoit JN: Myosin phosphorylation triggers actin polymerization in vascular smooth muscle. Am J Physiol Heart Circ Physiol 295: H2172-H2177, 2008.

33. Dubus I, L'Azou B, Gordien M, Delmas Y, Labouyrie JP, Bonnet J and Combe C: Cytoskeletal reorganization by mycophenolic acid alters mesangial cell migration and contractility. Hypertension 42: 956-961, 2003.

34. Lamalice L, Le Boeuf $F$ and Huot J: Endothelial cell migration during angiogenesis. Circ Res 100: 782-794, 2007.

35. Bergers G, Song S, Meyer-Morse N, Bergsland E and Hanahan D: Benefits of targeting both pericytes and endothelial cells in the tumor vasculature with kinase inhibitors. J Clin Invest 111: 1287-1295, 2003

36. Raza A, Franklin MJ and Dudek AZ: Pericytes and vessel maturation during tumor angiogenesis and metastasis. Am J Hematol 85: 593-598, 2010.

37. Hirase $\mathrm{T}$ and Node K: Endothelial dysfunction as a cellular mechanism for vascular failure. Am J Physiol Heart Circ Physiol 302: H499-H505, 2012. 